NIHR Health Protection Research Unit in Emergency Preparedness and Response, Norwich Medical School, University of East Anglia, Norwich, UK

Paul.Hunter@uea.ac.uk Cite this as: BMJ 2021;373:n958 http://dx.doi.org/10.1136/bmj.n958 Published: 14 April 2021

\section{Thrombosis after covid-19 vaccination}

\author{
These rare events must not derail vaccination efforts
}

\section{Paul R Hunter professor in medicine}

Despite early confusion over efficacy and the initial paucity of data in older age groups, ${ }^{1}$ the Oxford-AstraZeneca vaccine (ChAdOx1) has been shown to be highly effective, especially at preventing severe disease and death from covid-19, even after a single dose. ${ }^{2}$ Without the AstraZeneca vaccine it is doubtful that hospital admissions in the UK would have fallen as much as they have, delaying release from lockdown.

During March, however, concerns were raised over possible thromboses after immunisation with the AstraZeneca vaccine. One of the first official reports from the European Medicines Agency, on 10 March, noted four cases of thrombosis in people immunised with a single batch of the vaccine in Austria, including at least two severe cases and one death. ${ }^{3}$ The batch was withdrawn from use. The following day reports emerged of a death in Denmark and the country suspended use of the vaccine to allow time for investigation. Several other countries followed suit. ${ }^{4}$

Subsequently, the focus of attention narrowed from thrombosis in general to cerebral venous sinus thrombosis (CVST), a rare condition with a background incidence of about 15 cases per million people each year according to recent studies from Australia and the Netherlands. ${ }^{5}$ CVST is a rare cause of stroke that generally affects younger adults and women more than men. Important risk factors are pregnancy and hormonal contraception. ${ }^{5}$

Proving cause and effect is never easy, especially for rare events. Chance clusters of rare events occur quite commonly in observations or analyses of large groups. ${ }^{6}$ Nevertheless, the balance of evidence was clearly shifting at the beginning of April. Increased reporting of CVST in the UK as well as in Europe, along with the almost total absence of cases after immunisation with Pfizer or Moderna vaccines were strong indicators that this may be a real association. That many of those affected also had thrombocytopenia, which is not normally found in CVST, was an additional pointer that this was not a random association.

Both European and UK medicines regulators reported their conclusions on 7 April. 7 From the EMA briefing we learnt that other blood clots associated with thrombocytopenia were also being reported following the AstraZeneca vaccine, including arterial thromboses and splanchnic vein thrombosis. ${ }^{8}$ The EMA compared the clinical picture to a similar heparin induced thrombocytopenia, ${ }^{9}$ and two recently published case series have confirmed this similarity. ${ }^{10}{ }^{11}$ All patients in each series had high levels of antibodies against antigenic complexes of platelet factor $4(\mathrm{PF} 4)$, as seen in heparin induced thrombocytopenia. None of the patients had received heparin. ${ }^{1011}$ Further studies in two patients confirmed PF 4 dependent platelet activation. ${ }^{10}$ The authors coined the term vaccine induced immune thrombotic thrombocytopenia for this condition. Potential treatment options include high dose immunoglobulins and certain non-heparin anticoagulants. ${ }^{10}$

The UK's Medicines and Healthcare Products Regulatory Agency had received 79 reports of thrombosis associated with low platelets by 31 March, of which 44 were CVST. ${ }^{12}$ Of these 79 cases, 51 (13 fatal) were in women and 28 (six fatal) in men. So far all of the UK cases have occurred after the first dose. The risk was higher in the younger age groups, starting at 1.1 serious harm events for 100 ooo immunised people among those aged 20-29 years and falling to $0.2 / 100$ ooo in those aged 60-69. For comparison, in women taking hormonal contraceptives the risk of thrombosis is about $60 / 100$ ooo person years and risk of fatal pulmonary embolism is about $1 / 100$ 000. ${ }^{1314} \mathrm{In}$ most adult age groups, the benefits of the AstraZeneca vaccine far outweigh the risks. The exception is the 20-29 year age group, for which the risk-benefit equation is more finely balanced when community transmission is low.

At the time of writing, six cases of serious thrombosis with thrombocytopenia had been reported after the use of the Johnson \& Johnson (Janssen) covid-19 vaccine. To date about seven million doses of this vaccine have been administered in the US, and rollout has been paused pending review of the data. ${ }^{15}$ The Janssen vaccine has not yet been licensed in the UK, although 30 million doses are on order. ${ }^{16}$

There is still much we do not know about thromboses potentially linked to covid-19 vaccination, and much of the information used by the regulatory authorities in forming their opinions has not been made public. Regulatory agencies in Europe and the UK have acted with commendable swiftness, but they must publish not only their conclusions but also their data and analyses.

It remains the case that the benefits of the AstraZeneca vaccine far outweigh the risks for all adult age groups, especially when the potential for long covid is considered. People should accept vaccination when it is offered but seek medical advice if they develop the symptoms listed by Public Health England (box 1). ${ }^{12}$ If this issue delays the rollout of vaccines or stops some people accepting vaccination, many more preventable deaths could occur. The best covid-19 vaccine available is the one you can get today. 


\section{Box 1: Symptoms of concern: Public Health England ${ }^{12}$}

- A new, severe headache which is not helped by usual painkillers or is getting worse

- A headache that seems worse when lying down or bending over

- An unusual headache that may be accompanied by:

- Blurred vision, nausea, and vomiting

- Difficulty with your speech

- Weakness, drowsiness, or seizures

- New, unexplained pinprick bruising or bleeding

- Shortness of breath, chest pain, leg swelling, or persistent abdominal pain

Competing interests: The $B M$ / has judged that there are no disqualifying financial ties to commercial companies. PRH is funded by the National Institute for Health Research Health Protection Research Unit (NIHR HPRU) in Emergency Preparedness and Response at King's College London in partnership with Public Health England (PHE) and collaboration with the University of East Anglia. The views expressed are those of the author and not necessarily those of the NHS, the NIHR, UEA, the Department of Health, or PHE. The BM/policy on financial interests is here: https://www.bmj.com/sites/default/files/attachments/resources/2016/03/16-current-bmj-education-coi-form.pdf.

Provenance and peer review: Commissioned; not externally peer reviewed.

1 Hunter P. Oxford COVID-19 vaccine: newly published results show it is safe - but questions remain over its efficacy The Conversation2020 Dec 9.https://theconversation.com/oxford-covid19-vaccine-newly-published-results-show-it-is-safe-but-questions-remain-over-its-efficacy-151774

2 Bernal JL, Andrews N, Gower C, etal. 2021. Early effectiveness of COVID-19 vaccination with BNT162b2 mRNA vaccine and ChAdOx1 adenovirus vector vaccine on symptomatic disease, hospitalisations and mortality in older adults in England.MedRxiv 2021. [Preprint.] https://www.medrxiv.org/content/10.1101/2021.03.01.21252652v1

3 EMA. Covid-19 vaccine AstraZeneca: PRAC preliminary view suggests no specific issue with batch used in Austria, 10 March 2021. https://www.ema.europa.eu/en/news/covid-19-vaccine-astrazeneca-prac-preliminary-view-suggests-no-specific-issue-batch-used-austria

4 AstraZeneca vaccine: timeline of what's happened since European countries suspended use of Covid jab. ITV News 2021 Apr 7. https://www.itv.com/news/2021-04-07/astrazeneca-vaccinetimeline-of-whats-happened-since-european-countries-suspended-use-of-covid-jab

5 Medicherla CB, Pauley RA, de Havenon A, Yaghi S, Ishida K, Torres JL. Cerebral venous sinus thrombosis in the covid-19 pandemic. J Neuroophthalmol 2020;40:457-62. doi: 10.1097/WNO.0000000000001122 pmid: 33186264

6 Center for Disease Control. Guidelines for investigating clusters of health events. MMWR Recomm Rep 1990;39(RR-11):1-23.pmid: 2117247

7 Mahase E. AstraZeneca vaccine: Blood clots are "extremely rare" and benefits outweigh risks, regulators conclude. BMJ2021;373:n931. doi: 10.1136/bmj.n931. pmid: 33832929

8 EMA. AstraZeneca's COVID-19 vaccine: EMA finds possible link to very rare cases of unusual blood clots with low blood platelets. 2021. https:/www.ema.europa.eu/en/news/astrazenecascovid-19-vaccine-ema-finds-possible-link-very-rare-cases-unusual-blood-clots-low-blood

9 Greinacher A. Clinical practice. heparin-induced thrombocytopenia. NEngl/J Med 2015;373:252-61. doi: 10.1056/NEJMcp1411910 pmid: 26176382

10 Greinacher A, Thiele T, Warkentin TE, Weisser K, Kyrle PA, Eichinger S. Thrombotic thrombocytopenia after ChAdOX1 nCov-19 vaccination. N Engl/ Med 2021. do: 10.1056/NEJMoa2104840 pmid: 33835769

11 Schultz NH, Sørvoll IH, Michelsen AE, etal. Thrombosis and thrombocytopenia after ChAdOx1 nCoV-19 vaccination. N Engl J Med 2021. doi: 10.1056/NEJMoa2104882 pmid: 33835768

12 Public Health England. Guidance: covid-19 vaccination and blood clotting. 2021. https://www.gov.uk/government/publications/covid-19-vaccination-and-blood-clotting/covid-19vaccination-and-blood-clotting

13 Lidegaard Ø, Løkkegaard E, Svendsen AL, Agger C. Hormonal contraception and risk of venous thromboembolism: national follow-up study. BMJ 2009;339:b2890. doi: 10.1136/bmj.b2890 pmid: 19679613

14 Parkin L, Skegg DC, Wilson M, Herbison GP, Paul C. Oral contraceptives and fatal pulmonary embolism. Lancet 2000;355:2133-4. doi: 10.1016/S0140-6736(00)02382-5 pmid: 10902629

15 Centre for Disease Control. DC Joint CDC and FDA Statement on Johnson \& Johnson covid-19 vaccine. https://www.cdc.gov/media/releases/2021/s0413-J-vaccine.html

16 Covid: Which vaccines has the UK bought and how many doses of each? ITV News 2021 Feb 1 https://www.itv.com/news/2021-02-01/deal-for-promising-covid-vaccine-puts-uks-total-doseorder-at-more-than-400m and print the article for any lawful, non-commercial purpose (including text and data mining) provided that all copyright notices and trade marks are retained. 